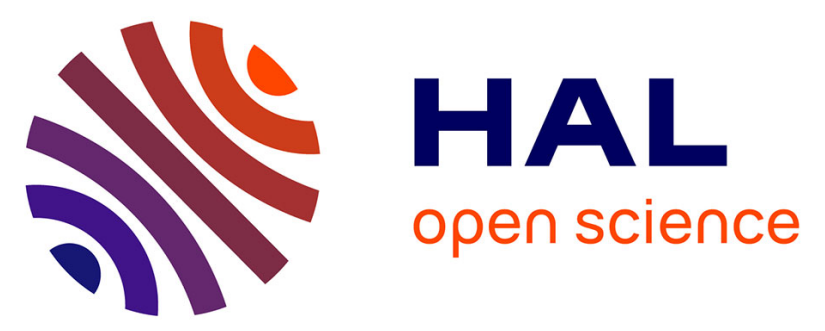

\title{
Influence of Personality Traits and Body Awareness on the Sense of Embodiment in Virtual Reality
}

\author{
Diane Dewez, Rebecca Fribourg, Ferran Argelaguet Sanz, Ludovic Hoyet, \\ Daniel Mestre, Mel Slater, Anatole Lécuyer
}

\section{- To cite this version:}

Diane Dewez, Rebecca Fribourg, Ferran Argelaguet Sanz, Ludovic Hoyet, Daniel Mestre, et al.. Influence of Personality Traits and Body Awareness on the Sense of Embodiment in Virtual Reality. ISMAR 2019 - 18th IEEE International Symposium on Mixed and Augmented Reality, Oct 2019, Beijin, China. pp.1-12. hal-02385783

\section{HAL Id: hal-02385783 \\ https://hal.inria.fr/hal-02385783}

Submitted on 29 Nov 2019

HAL is a multi-disciplinary open access archive for the deposit and dissemination of scientific research documents, whether they are published or not. The documents may come from teaching and research institutions in France or abroad, or from public or private research centers.
L'archive ouverte pluridisciplinaire HAL, est destinée au dépôt et à la diffusion de documents scientifiques de niveau recherche, publiés ou non, émanant des établissements d'enseignement et de recherche français ou étrangers, des laboratoires publics ou privés. 


\title{
Influence of Personality Traits and Body Awareness on the Sense of Embodiment in Virtual Reality
}

\author{
Diane Dewez ${ }^{1 *} \quad$ Rebecca Fribourg ${ }^{1 *} \quad$ Ferran Argelaguet ${ }^{1 *} \quad$ Ludovic Hoyet $^{1 *} \quad$ Daniel Mestre $^{2 \dagger}$ \\ Mel Slater ${ }^{3 \ddagger} \quad$ Anatole Lécuyer ${ }^{1 *}$ \\ ${ }^{1}$ Inria, Univ Rennes, CNRS, IRISA, France \\ 2 Aix-Marseille University/ISM, CNRS, France \\ ${ }^{3}$ University of Barcelona, Event Lab, Department of Clinical Psychology and Psychobiology, Spain
}
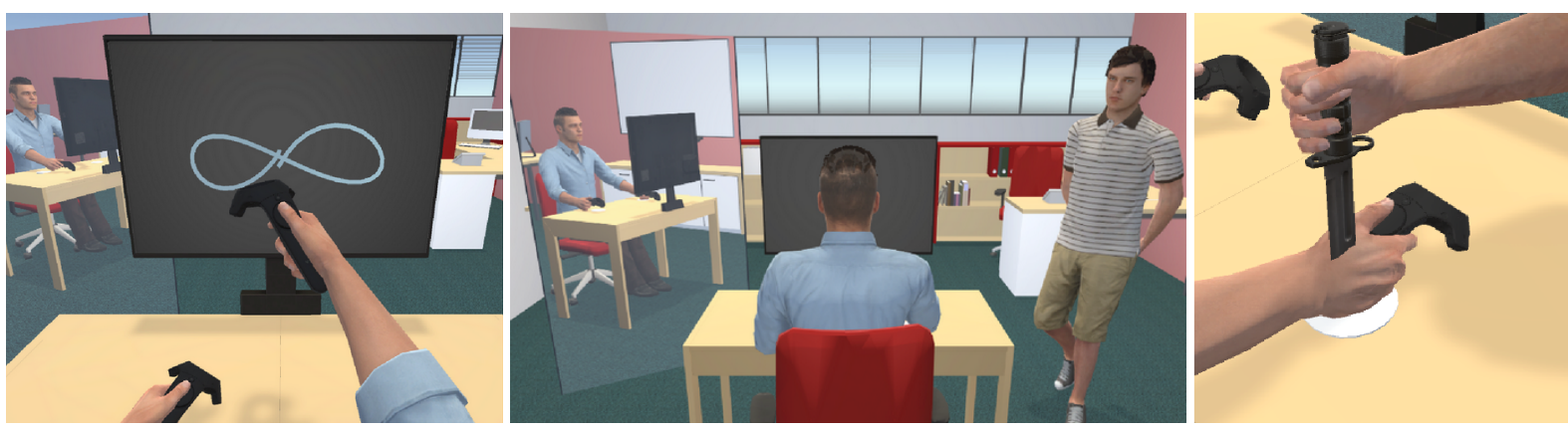

Figure 1: From left to right: an example of a trajectory to draw during the experimental task; A view of the scene from behind; Another virtual character stabbing the participants' virtual hand at the end of the experiment to measure their response to the threat on their virtual body.

\begin{abstract}
With the increasing use of avatars (i.e. the virtual representation of the user in a virtual environment) in virtual reality, it is important to identify the factors eliciting the sense of embodiment or the factors that can disrupt this feeling. This paper reports an exploratory study aiming at identifying internal factors (personality traits and body awareness) that might cause either a resistance or a predisposition to feel a sense of embodiment towards a virtual avatar. To this purpose, we conducted an experiment $(n=123)$ in which participants were immersed in a virtual environment and embodied in a gender-matched generic virtual avatar through a head-mounted display. After an exposure phase in which they had to perform a number of visuomotor tasks (during 2 minutes) a virtual character entered the virtual scene and stabbed the participants' virtual hand with a knife. The participants' sense of embodiment was measured, as well as several personality traits (Big Five traits and locus of control) and body awareness, to evaluate the influence of participants' personality on the acceptance of the virtual body. The major finding of the experiment is that the locus of control is linked to several components of embodiment: the sense of agency is positively correlated with an internal locus of control and the sense of body ownership is positively correlated with an external locus of control. Interestingly, both components are not influenced by the same traits, which confirms that they can appear independently. Taken together our results suggest that the locus of control could be a good predictor of the sense of embodiment when the user embodies an avatar with a similar physical appearance. Yet, further studies are required to confirm these results.
\end{abstract}

\footnotetext{
*e-mail: name.surname@inria.fr

†e-mail: daniel.mestre@univ-amu.fr

†e-mail: melslater@ub.edu
}

Index Terms: Human-centered computing-Human computer interaction ( $\mathrm{HCI}$ - - HCI design and evaluation methods-User studies; Human-centered computing-Human computer interaction (HCI) Interaction paradigms - Virtual reality

\section{INTRODUCTION}

When immersed in a virtual environment (e.g. using an HMD) the virtual representation of the user (the avatar) serves as the link between the real and the virtual world, as users' actions in the real world are mapped to their virtual counterpart. The avatar can enhance perception of the virtual environment [12,47] and user performance [57], but can also improve user experience (e.g., by increasing presence [66] or changing users' behaviour [78]). Yet, in order to fully exploit the benefits of the avatar, users must clearly feel that the avatar is their own representation over which they have the control, in other words, they have to "embody" it [51]. Understanding this process can contribute to develop better applications involving the use of avatars like in health [44], cinema [8] or social environments [23].

The sense of embodiment in virtual environments is commonly defined as the combination of three sub-components: self-location, body ownership and agency [31]. These components represent three different aspects of embodiment, which can be correlated or appear separately, depending on the situation [42]. Most studies on virtual embodiment have explored factors linked to the avatar itself (e.g., appearance [3,51], realism [45]) or to the apparatus (e.g., degree of control [11], nature of the stimulation [33]). However, these factors are "external factors", i.e., are mostly linked to the avatar itself or to the experiment protocol, but not to the "internal" user state (e.g. personality or background experiences). Indeed, while most studies are able to show general trends of the influence of such "external" factors, the inter-user variability remains non-negligible. In practice, we can observe that some people easily believe in the illusion, while others are in the contrary totally refractory. This observation led us to investigate how individual differences could influence the sense of embodiment in virtual reality (VR). 
In this paper, we therefore present an exploratory experiment where we investigated the link between "internal" factors (personality traits and body awareness) and the sense of embodiment. One hundred and twenty three participants were embodied in a virtual avatar while taking part in the experiment, which was divided into three phases: adaptation, induction and threat. In the adaptation phase participants were able to freely explore the environment and their avatar, in the induction phase participants had to reproduce a series of visuomotor tasks (see Figure 1, left) and in the threat phase, a virtual character appeared in the environment and threatened the avatar's hand with a knife (see Figure 1, right). At the end of the experiment, users were asked to fill in an embodiment questionnaire, as well as four additional questionnaires assessing different "internal" dimensions about them: the Big Five Inventory (BFI), the Ten-Item Personality Inventory (TIPI), the Internality, Powerful others and Chance scale (IPC scale) and the Body Awareness Questionnaire (BAQ).

Our main result is that the locus of control (i.e., the degree to which people believe that they have control over the outcome of events in their lives, as opposed to external forces beyond our control), plays an important role in explaining the sense of embodiment. More precisely, we demonstrated that an internal locus of control is positively correlated with the sense of agency, but that an external locus is positively correlated with the sense of ownership. We however did not find strong correlations between the sense of embodiment and either the Big Five personality traits or body awareness. These results contribute to a better understanding of the influence of "internal factors" on the sense of embodiment and pave the way to further studies exploring this matter. In summary, our main contributions are therefore 1) the exploration of how personality traits and body awareness can influence the sense of embodiment through a large-scale VR experiment involving one hundred and twenty three participants, and 2) the identification of a main personality trait (the locus of control) which seems to be a principal influence on the sense of embodiment in VR.

The remainder of the paper is structured as follows. First, Section 2 reviews related work on the role of inter-personal differences in presence and on the sense of embodiment. Then, Section 3 describes the experiment, including the questionnaires we used. Section 4 describes the results of the experiment, which are discussed in Section 5. Finally, Section 6 provides the concluding remarks.

\section{Related Work}

This section reviews a number of works which have explored the role of inter-personal differences (e.g. personality) in VR. Because of the amount of work that was done in the past on the influence of interpersonal differences on presence, we first look at this specific aspect of the related work. However, as presence is typically linked to the perception of the virtual environment itself, and not specifically to the perception of the avatar, we then review in a second stage the major concepts and key studies on virtual embodiment, which is the interest of this paper, as well as the few studies which have tried to link inter-personal differences and embodiment.

\subsection{Role of Inter-personal Differences in Presence}

Presence, the feeling of being there, has been widely studied in VR [67], in particular personality models with different dimensions like the OCEAN model have been used in order to characterise interpersonal differences. The OCEAN model, also known as the "Big Five" personality traits, is a taxonomy of personality traits that uses common language descriptors in order to identify five personality dimensions: Openness to experience, Conscientiousness, Extraversion, Agreeableness and Neuroticism. For example, it was found that agreeableness was positively associated with spatial presence [58] Weibel et al. [76] studied the link between the Big Five traits and immersive tendency (which contributes to the sense of presence [40]) and found that openness, extraversion and neuroticism were positively correlated with immersive tendency. However, a number of studies have found contradictory results. For example, regarding the influence of extraversion, it was found to be positively [36] or to be negatively correlated [29] with presence.

In addition to the "Big Five", other personality traits that have been investigated are absorption (the disposition for having episodes of "total" attention that fully engage one's representational resources [69]) and dissociation (the lack of normal integration of thoughts, feelings, and experiences into the stream of consciousness and memory [43]). They were first both found associated with reality judgment [4]. Then their influence on presence was studied and they were sometimes both found positively correlated with presence [58], sometimes only dissociation was associated with presence [49] or neither of them was correlated [54]. Kober and Neuper [32] found that absorption was a good predictor of presence, no matter what presence questionnaire was used. Moreover, empathy is another trait which has been studied in the past, and demonstrated to be related to feeling a higher sense of presence [40,50,59].

Finally, the locus of control was also demonstrated to have an influence on the sense of presence. However contradictory results were found, namely that either an external [49] or internal [74] locus of control was improving presence depending on the study.

\subsection{The Sense of Embodiment}

The phenomenon of embodiment has multiple definitions in cognitive sciences, one of them being that " $\mathrm{E}$ is embodied if and only if some properties of $\mathrm{E}$ are processed in the same way as the properties of one's body" [10]. The rubber-hand illusion (RHI) experiment [5] is one of the most famous works showing the possibility to create an illusion of owning a body which is not ours (i.e. feeling that the rubber hand is our own hand). Further experiments have also explored full-body embodiment, such as being embodied in a full-size mannequin [53]. Overall, the research on embodiment has been facilitated with the emergence of VR, which permits to investigate in a more controlled manner and in more depth the necessary conditions to elicit such illusion.

In VR, the sense of embodiment has been decomposed into three main dimensions [31]: (1) the sense of self-location, i.e. the feeling of being located inside the avatar's body, (2) the sense of agency, i.e. the feeling of being in control of the avatar and having an influence on the virtual environment, and (3) the sense of body ownership, i.e. the feeling of owning the avatar's body. In the following Sections, we review works aiming at better understanding the sense of embodiment in VR, focusing either on "external" (i.e. depending on the experimental setup or the avatar itself) or "internal" factors (i.e. depending on the state of the subject).

\subsubsection{External Factors}

VR enables the full control of a wide number of experimental factors, from the stimulation protocol to the appearance and morphology of users' avatar, which has resulted in a notable body of literature examining the impact of such factors on the perceived sense of embodiment.

The first studies conducted in VR with respect to virtual embodiment, focused on the sense of ownership, trying to reproduce the rubber-hand illusion in VR [64]. In particular, Kokkinara et al. [33] showed that in order to feel body ownership in VR, the synchronicity of visuotactile or visuomotor stimulation are needed, and that visuomotor feedback has more influence on body ownership than visuotactile stimulation. Despite the fact that it is possible to feel some ownership when seeing only virtual hands and feet [34], the avatar's appearance has been shown to be of importance to maximise the ownership illusion. For example, it is usually stronger with an avatar with coherent clothes or skin tone [45], and potentially even higher with a self-representation [21]. Furthermore, VR also enables to 
embody users in avatars which differ from their self-representation, such as embodying an avatar with the opposite gender [65], with a child's body [3], with a non-matching skin color [51] or even with three arms [37]. These works showed in general that it was possible to generate a sense of embodiment.

Regarding the sense of agency, an important factor is the synchrony between users' action and the visual feedback [26]. While users can still feel in control when the offset between the action and the feedback is slightly manipulated, the sense of agency is however lost when the visual feedback becomes too obviously asynchronous [11]. Regarding visual appearance, the sense of agency could also be elicited even with point-line avatars [77] and with virtual limbs in implausible positions [71]. Also, the sense of agency is strongly coupled with the interaction capabilities of the avatar [1]

Finally, regarding the sense of self-location, studies have shown that third-person perspectives usually provokes a drop in the sense of self-location $[20,46]$. However, with a synchronous visuotactile stimulation, it is possible to experience a progressive shift toward the virtual body seen from a third person point of view [38].

\subsubsection{Internal Factors}

External factors focus on different experimental conditions (e.g. stimulation, appearance, perspective), yet, they rarely consider individual differences. Internal factors, such as body awareness [9] and personality traits [26] have been studied in relation to the sense of embodiment.

However, the majority of the works addressing such internal factors have mainly focused on the RHI in the physical world. The influence of body awareness, a cognitive ability that makes us aware of our body processes, has been studied but no correlation was found with the strength of RHI [9]. Regarding personality and RHI, it has been found that the RHI is stronger for empathic people [2,61] The sense of ownership in the RHI was also found correlated with traits like the Novelty Seeking trait (from the TCI-R questionnaire) or Psychoticism (from the SCL-90-R questionnaire) [35]. Also, higher responses to the RHI have been reported for people suffering from personality or psychotic disorders: dissociative subtype of post-traumatic stress disorder (PTSD) [56], schizophrenia [52, 70] and schizotypal personality disorder $[2,73]$.

Finally, recent works have started to focus on the potential role of personality traits in virtual embodiment. One example being the work of Jeunet et al. [26] which showed that the feeling of agency is linked to an internal locus of control.

The literature review thus showed both a clear interest and important results regarding the influence of personality on user's sense of presence in VR and on users' sense of embodiment in the physical world. Some more recent work also revealed an influence of the locus of control, a personality trait, on the sense of embodiment in VR. This last result highlighted the potential role of individual differences in the elicitation of the sense of embodiment in VR and in this way, raised the concern of exploring deeper their possible link with the sense of embodiment in VR. For this reason, the presented study explores the influence of a wider range of personality traits and of body awareness on the sense of embodiment in VR.

\section{EXPERIMENT}

In order to explore the potential influence of personality traits and body awareness on the sense of embodiment, we conducted an experiment in which participants were embodied in a gender-matched avatar. The main experimental task was a visuomotor task involving the upper-body in order to elicit the sense of embodiment over the avatar. After the experiment, participants were asked to fill in subjective questionnaires on embodiment and presence, as well as several personality and body awareness questionnaires.

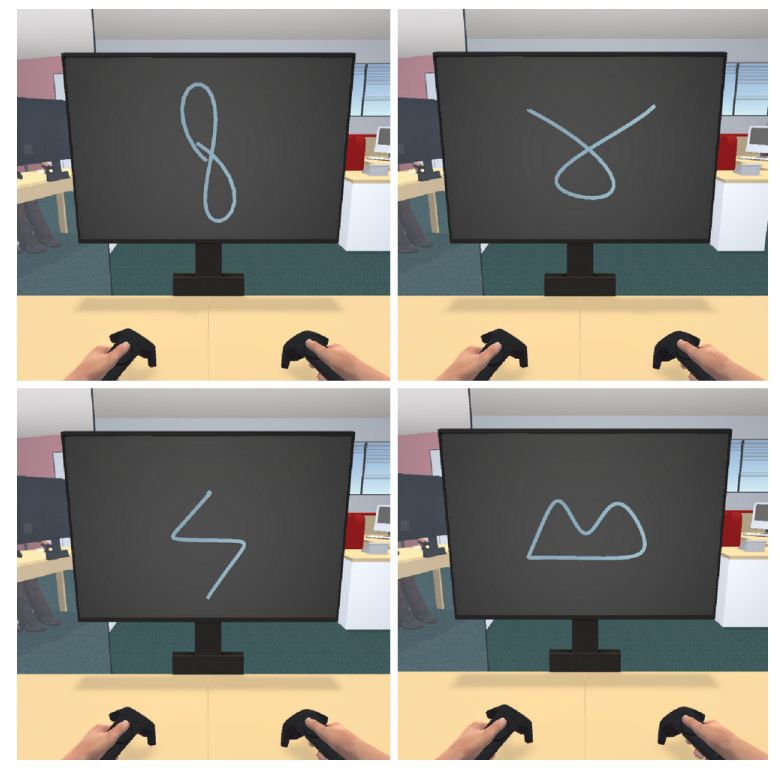

Figure 2: Examples of four trajectories that participants were instructed to perform during the experiment with either their left or their right hand

\subsection{Participants}

One hundred and twenty three participants (age $\min =18, \max =60$, avg $=30.3 \pm 9.0,58$ women and 65 men) took part in our experiment. The majority of them were students and staff from our research center. All participants freely volunteered for the experiment and most of them were curious about virtual reality. They did not receive course credits nor economical compensation. They were all naive to the purpose of the experiment and had normal or correct-to-normal vision. People wearing glasses could keep them if they were not generating any discomfort. All participants gave written and informed consent. The study conformed to the declaration of Helsinki, and was approved by the local ethical committee. Seventy-six participants reported to have no previous experience in VR, twenty-five to have some previous experiences in VR and twenty-two to be experts.

\subsection{Experimental Protocol}

Before the experiment: Upon their arrival, participants were first briefed about the experiment, read and signed the consent form. They were then equipped with the HMD and the controllers, were asked to sit on a chair in front of the table where the experiment would be conducted, and a calibration phase was performed to adapt the avatar to their dimensions. More precisely, the global scale of the avatar was first adapted to match the height of the participant. Then, participants were asked to take a seated T-pose (reach arms on the side), in order to measure their arm span using both controllers. The distance between the two controllers was therefore used to adjust the avatar's arm length, while the headset position was used to scale the avatar's spine so that the avatar's head position matched the user's one. Participants were then asked to freely discover the environment. We did not impose a fixed time during the acclimation phase. Yet, all participants were encouraged to explore the scene, their avatar, and to look into the mirror. When they were ready, they could start the task.

Experimental task: Participants sat in front of a real table and saw a similar co-located virtual table, while being immersed in the virtual environment from a first-person perspective. They were asked to put their hands on the virtual table (on two white spots) receiving by this 


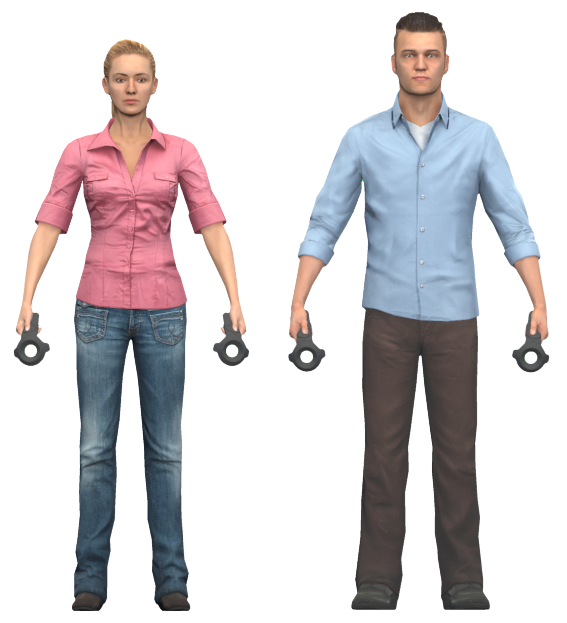

Figure 3: The two avatar models used in our experiments, which were matched to the gender of the participant.

occasion passive haptic feedback from the physical table. They hold in their hands the real controllers that were also represented in the virtual world for coherence concern. A virtual screen was positioned in front of them, on the table, and a virtual mirror was located on their left (Figure 1). We chose to use a mirror as it is supposed to induce a greater sense of ownership $[19,25]$. Also, we decided to induce the sense of ownership using visuomotor feedback since it has been shown to be stronger than visuotactile synchronisation to induce body ownership [33].

2D trajectories were displayed on the screen (see Figure 2), which participants were instructed to reproduce in front of them, using either their right or left hand according to the instruction provided. The trajectories presented were chosen to be relatively simple (number eight, circle, triangle, etc) to avoid a high cognitive load, which could have distracted participants from their avatar and the environment. After each drawing, they had to put back their hands on the white spots on the table. The task lasted two minutes during which participants saw their avatar moving synchronously according to their movements. After the achievement of the task, a virtual character entered the room and stabbed the virtual hand with a knife. We measured the reaction to the threat (hand motion), in order to inspect its potential correlation with the sense of ownership.

After the experiment: Participants were asked to fill in a number of questionnaires. First they filled in a demographic questionnaire, then they answered questions about embodiment, as well as questions about presence. They also filled in several personality questionnaires, and a body awareness questionnaire. Collected data are presented in more detail in Section 3.4.

\subsection{Apparatus}

The experiment was developed using Unity 2018.1.6f1. Participants saw the virtual environment through an HTC Vive PRO HMD, while their hand movements were tracked using the Vive controllers. The FinalIK plugin was used to animate the participants' avatar with Inversed Kinematics and to provide visuomotor feedback, based on the participants' head (HMD) and hands (controllers) movements. During the experiment, two avatar models were used to match the participant's gender (see the male and female avatars in Figure 3). Because appearance is a major contributor to the sense of embodiment, using personalised avatars might lead to high embodiment ratings for most participants [75], which would prevent us from exploring the influence of individual traits on embodiment. We therefore decided to use gender-matched generic avatars to obtain a higher variability in embodiment ratings, i.e., to obtain both low and high embodiment ratings across participants. Also, the animation of the virtual character threatening the participant's hand at the end of the task was recorded using an Xsens motion capture system prior to the experiment, and mapped onto another virtual character (see Figure 1, right).

\subsection{Collected Data}

\subsubsection{Embodiment and Presence Questionnaires}

To measure embodiment, participants were asked to fill in the standardised subjective questionnaire proposed by Gonzalez-Franco and Peck [18]. It is composed of questions divided in several categories: body ownership, agency, tactile sensations (not used in our experiment), location, external appearance and response to external stimuli (referred to as threat perception in this paper). Participants therefore answered 19 questions on a 7-point Likert scale.

Given the shortness (6 questions) of the Slater-Usoh-Steed (SUS) presence questionnaire [72] typically used in such experiments in the past, we also decided to include this questionnaire. People rated each question on a 7-point Likert scale. Our goal was to confirm previous results linking personality to presence, despite the already important number of questionnaires in our study. In particular, assessing how similar our results are to previous work on the relation between personality and presence would also be of value to further validate potential results on the sense of embodiment.

\subsubsection{Behavioural Response}

In addition to the embodiment questionnaire, we recorded participants' hand movements during the threat (character stabbing the participant's virtual hand at the end of the experiment), in order to evaluate how much participants considered the avatar to be their own body. In this situation, typically used in previous studies to provide another measure of the sense of embodiment, participants who feel embodied in their avatar are more likely to remove their hand [15], suggesting that they consider the virtual body to be their own.

\subsubsection{Psychological Variables}

As we wished to explore the effect of several aspects of personality and ability on embodiment, we selected a number of questionnaires which participants filled in after the experiment. These questionnaires were chosen to explore aspects we believed could influence embodiment, while ensuring that the duration for answering all these questionnaires was reasonable. Our choice was also based on the few studies conducted on internal factors, using for example body awareness and locus of control as independent variables. Four questionnaires were therefore selected (BFI, TIPI, IPC, BAQ), which are presented below with our corresponding exploratory questions of interest. Research questions were preferred instead of precise hypotheses because of the lack of literature and the wide range of traits evaluated in our experiment. On average, participants took 20 minutes to answer all the questionnaires. It is also important to mention that the experiment was conducted on a French campus, and that we therefore used the French validated translation of these international questionnaires in our experiment. All the Likert scales used are the ones proposed in each validated questionnaire, going from the lower bound (strong disagreement) to the upper bound (strong agreement).

Big Five Personality traits taxonomy is a common way of describing one's personality, even though not the only one that exists. In this model, called the Big Five or OCEAN model [17], personality is typically described by five dimensions, which are Openness to experience, Conscientiousness, Extraversion, Agreeableness and Neuroticism. While several questionnaires of various complexity exist to assess these personality dimensions (e.g., 240-item NEO PI-R, 44-item BFI) we chose two questionnaires to use in our experiment. 
First, we used the 44-item Big Five Inventory (BFI) [27] adapted to French by Plaisant et al. [55], where each item is rated on a 5point Likert scale. This is a relatively short questionnaire, compared for example to the 240-item NEO PI-R questionnaire, but still quite complete [28], and used in research [7,24]. It therefore seemed more adapted to an experiment involving several questionnaires. In this regard, a first question of interest was to study whether some personality traits were potentially correlated with the different components of embodiment (Q1).

However, despite the popularity of the BFI questionnaire and its relatively short length (44 items), being able to evaluate quickly how a user's personality traits would affect embodiment prior to a VR experience would be greatly improved if shorter questionnaires could be used. Therefore, we decided to include a second personality questionnaire, namely the Ten Item Personality Inventory (TIPI) [22], and used the French version [68], where each item is rated with a 7-point Likert scale. In particular, our goal was to study the extent to which the TIPI questionnaire would enable us to explain embodiment felt in VR compared to the more complete BFI questionnaire (Q2).

Our research questions related to the influence of Big Five personality traits on the sense of embodiment were therefore:

\section{Q1: Do some of the users' Big Five traits are correlated with their sense of embodiment in VR?}

Q2: Do TIPI and BFI questionnaires show similar personality traits correlations with the sense of embodiment in VR?

Locus of Control (LoC) (i.e., the degree to which people believe that they have control over the outcome of events in their lives as opposed to external forces beyond their control) is another set of personality traits, which was demonstrated to have an influence on the sense of presence $[49,74]$ and on the sense of agency [26]. We therefore included a questionnaire to measure one's LoC, and used the common 24-item IPC scale [39], translated in French by Loas [41], using a 6-point Likert scale. This questionnaire determines LoC according to three dimensions: Internal, Powerful others and Chance. These dimensions typically mean that someone with an external LoC will tend to think that everything happens because of fate (chance type of locus) or powerful people (powerful others type of locus), while someone with an internal $\mathrm{LoC}$ will tend to think that he can change events with his own will and actions.

As a previous study [26] showed that an internal LoC is positively correlated with the sense of agency, we expected to find the same results in our study (Q3). Moreover, while this seems in agreement with the fact that the LoC is directly related to the action, there is no information about the possible influence of $\mathrm{LoC}$ on the sense of ownership. Therefore, we investigate whether ownership could also be correlated with an internal LoC (Q4), since some studies found that the sense of ownership and the sense of agency are based on similar processes and can strengthen each other $[13,30]$.

Our research questions related to the influence of internal and external LoC on the sense of embodiment were therefore:

\section{Q3: Is an internal LoC positively correlated with the sense of agency, as previously found [26]?}

Q4: Is the sense of ownership also correlated with an internal LoC?

Body Awareness is a cognitive ability that makes us aware of our body processes. Because it can change the way we perceive our real body, there is a possibility that it could also influence the perception of our virtual body. While body awareness was not found to influence the RHI in the physical world [9], another study did show that the other way, it could be disturbed by the body ownership illusion [71]. Furthermore, to our knowledge, no studies were conducted to investigate its influence on the sense of embodiment in VR. We therefore decided to also include this personal ability in our study, and used the 18-item Body Awareness Questionnaire (BAQ) [62], where each item is rated on a 7-point Likert scale, translated in French by Dumont [14]. This questionnaire is a selfreport assessment of the body awareness, estimating the attention and consciousness we have of our body processes, often used in research because of its high reliability and validity compared to other self-report instruments [48].

Our research question related to the influence of body awareness on the sense of embodiment was therefore:

Q5: Is body awareness correlated with the sense of embodiment?

\section{Results}

In order to analyse the link between internal factors and the sense of embodiment, Section 4.1 first explores the relationship between the embodiment scores (ownership, agency, self-location, external appearance and threat perception) and the Big Five, IPC and body awareness data. The data from the TIPI questionnaire are not discussed as there were no significant results $(\mathbf{Q 2}$ is therefore answered negatively). Then, Section 4.2 analyses the behavioural responses and Section 4.3 the presence results.

\subsection{Embodiment}

Before conducting the following analyses, we analysed the potential effects of gender and experience in VR on the embodiment questionnaires. Regarding gender, we performed Mann-Whitney tests for each question trying to find significant differences over such potential confounding factors. The analysis only showed two significant differences for body ownership related questions $(\mathrm{O} 2$ and $\mathrm{O5}$ ) between male and female participants, while no significant differences were found for the rest of the questions and factors. A summary of embodiment answers is presented in Table 1, separated by men and women answers when relevant. In order to avoid that such differences add noise to the rest of the analysis, the population was split into two groups (men and women) for the body ownership analysis. Regarding experience in VR and video games, we used Pearson correlations to see a potential influence on embodiment. We only found a positive correlation between agency and the experience in video games. For this reason, experience in video games is only reported in the section of Agency.

As we ran the same analysis for each aspect of embodiment, we summarise the procedure here for clarity. More precisely, we ran a separate Polychoric Principal Components Analysis (Polychoric PCA) for each aspect of embodiment on the different questions, as Polychoric PCA takes into account the ordinal nature of Likert scales. This type of PCA has already been used in similar studies [63]. As mentioned previously, a separate Polychoric PCA was run on men and women data in the case of ownership. As proposed in the standard questionnaire [18], we used the empirical Kaiser criterion to automatically select the number of principal components explaining sufficient amounts of variance, then performed a PCA with this number of components using an oblimin rotation, enabling us to interpret the selected components (see the summary of the obtained components in Figure 4, and exact values in Appendix A). Pearson correlations were then computed (see summary in Table 2) to explore potential links between the different components of embodiment and the internal factors questionnaires results. As we did not find results for the sense of self-location, this part was removed from the analysis.

A multiple linear regression was performed when correlations were found for a given component, as in other cases it would be difficult to find a good model with variables that are not correlated 
Table 1: Statistical summary of the embodiment questionnaire responses, for each question we report the median and the first and third quartiles. If there was a significant difference between the men and women answers, we report the summary for each group. O: body ownership, A: agency, L: self-location, EA: external appearance, T: threat perception

\begin{tabular}{llc}
\hline \hline ID & Questions & $\begin{array}{c}\text { Median[Q1,Q3] } \\
\text { Wen }\end{array}$ \\
\hline O1 & I felt as if the virtual body was my body & $4[3,5]$ \\
O2 & I felt as if the virtual body I saw was someone else & $4[3,5]$ \\
O3 & It seemed as if I might have more than one body & $3[2,4]$ \\
O4 & I felt as if the virtual body I saw when looking in the mirror was my own body & $4,4]$ \\
O5 & I felt as if the virtual body I saw when looking at myself in the mirror was another person & $4,5]$ \\
A1 & It felt like I could control the virtual body as if it was my own body & $5[2,5]$ \\
A2 & The movements of the virtual body were caused by my movements & $6[3,6]$ \\
A3 & I felt as if the movements of the virtual body were influencing my own movements & $7[6,7]$ \\
A4 & I felt as if the virtual body was moving by itself & $2[1,4]$ \\
L1 & I felt as if my body was located where I saw the virtual body & $1[1,2]$ \\
L2 & I felt out of my body & $6[4,6.5]$ \\
EA1 & It felt as if my (real) body were turning into an "avatar" body & $2[1,4]$ \\
EA2 & At some point it felt as if my real body was starting to take on the posture or shape of the virtual body that I saw \\
EA3 & At some point it felt that the virtual body resembled my own real body, in terms of shape, skin tone or other visual features \\
EA4 & I felt like I was wearing different clothes from when I came to the experience & $2[1,5]$ \\
T1 & I felt that my own hand could be affected by the knife & $2[1,5]$ \\
T2 & I felt fear when I saw the knife & $3[1,5]$ \\
T3 & When the knife appeared above my hand, I felt the instinct to remove my hand from the table & $2[1,5]$ \\
T4 & I had the feeling that I might be harmed by the knife & $2[1,5]$ \\
\hline
\end{tabular}

with the studied component. We used a backward stepwise method to select the best predictors, using the Akaike Information Criterion (AIC), i.e. we started with all the variables and progressively removed them so as to minimise the AIC value. We chose the AIC over the adjusted $\mathrm{R}^{2}$ as it also accounts for the complexity of the model [16]. All the multiple linear regression models computed are summarised in Table 3.

\subsubsection{Body Ownership}

As answers to body ownership questions were significantly different for men and women, we did two separate analyses for men and women participants.

Men. Two components were selected $\left(\mathrm{O}_{P C 1, M}\right.$ and $\left.\mathrm{O}_{P C 2, M}\right)$, which explained $65 \%$ of the variance. $\mathrm{O}_{P C 1, M}$ was mainly influenced by the questions $\mathrm{O} 1, \mathrm{O} 2, \mathrm{O} 4$ and $\mathrm{O} 5$, while $\mathrm{O}_{P C 2, M}$ was mostly influenced by $\mathrm{O} 3$.

We only found a positive correlation between $\mathrm{O}_{P C 1 . M}$ and the chance type of LoC $(\mathrm{r}=0.248, \mathrm{p}=0.047)$. As we did not find correlations between $\mathrm{O}_{P C 2, M}$ and any of the variables, we do not consider it further.

We performed a multiple linear regression for $\mathrm{O}_{P C 1, M}$ using the different psychological variables. We obtained a model with internal LoC, chance LoC and body awareness (adjusted $R^{2}=0.169, p=$ 0.003).

Women. Two components were selected $\left(\mathrm{O}_{P C 1, F}\right.$ and $\left.\mathrm{O}_{P C 2, F}\right)$, which explain $63 \%$ of the variance. $\mathrm{O}_{P C 1, F}$ was mainly influenced by the questions $\mathrm{O} 1, \mathrm{O} 2$ and $\mathrm{O} 3$, while $\mathrm{O}_{P C 2, F}$ was mostly influenced by $\mathrm{O} 4$ and 05 .

Then, we found a negative correlation between openness and $\mathrm{O}_{P C 1, F}(r=-0.293, p=0.026)$, as well as positive correlations between $\mathrm{O}_{P C 2, F}$ and both the chance type $\operatorname{LoC}(r=0.366, p=0.005)$ and the powerful others $\operatorname{LoC}(r=0.427, p<0.001)$.

The linear regression for $\mathrm{O}_{P C 1, F}$ gave us a model with openness, conscientiousness, internal LoC, powerful LoC, chance LoC and body awareness (adjusted $R^{2}=0.239, p=0.002$ ).

\subsubsection{Agency}

One component was selected $\left(\mathrm{A}_{P C 1}\right)$ which explains $48 \%$ of the variance. It was mainly influenced by the questions $\mathrm{A} 1, \mathrm{~A} 2$ and A4. We found a positive correlation between $A_{P C 1}$ and the internal $\operatorname{LoC}(r=0.248, p=0.006)$. The linear model found for $\mathrm{A}_{P C 1}$ was composed of agreeableness, internal LoC and body awareness $\left(R^{2}=\right.$ $0.079, p=0.005)$. We also found a positive correlation between $\mathrm{A}_{P C 1}$ and the level of experience in video games $(r=0.184, p=$ 0.04).

\subsubsection{External Appearance}

One component was selected $\left(\mathrm{EA}_{P C 1}\right)$, which explains $51 \%$ of the variance and was influenced positively by all the questions on appearance (EA1 to EA4). We only found correlations with the internal $\operatorname{LoC}(r=0.195, p=0.031)$ and chance LoC $(r=0.201, p=0.026)$.

However, as it seemed surprising that external appearance was simultaneously influenced by opposite (i.e., internal and external) types of LoC, we performed further Pearson correlations separately on the male and female populations, and found that the external appearance was more strongly related to the internal LoC for men $(r=0.306, p=0.013)$ and to the chance $\operatorname{LoC}(r=0.311$, $p=0.017)$ for women.

We performed two multiple linear regressions, by separating male and female populations. For men, the optimised model was composed of neuroticism, internal LoC and chance LoC (adjusted $\left.R^{2}=0.169, p=0.002\right)$. For women, the optimised model was only composed of chance LoC (adjusted $R^{2}=0.081, p=0.017$ ).

\subsubsection{Threat Perception}

One component was selected $\left(\mathrm{T}_{P C 1}\right)$, which explains $84 \%$ of the variance. All the questions about threat perception (T1 to T4) contributed positively to this component. A positive correlation was found with neuroticism $(r=0.258, p=0.004)$. The linear regression gave us a model with agreeableness and neuroticism (adjusted $R^{2}=0.088, p=0.001$ ).

\subsection{Threat Response}

In order to evaluate participants' response to the threat in a more objective manner, we also computed their accumulated right hand 

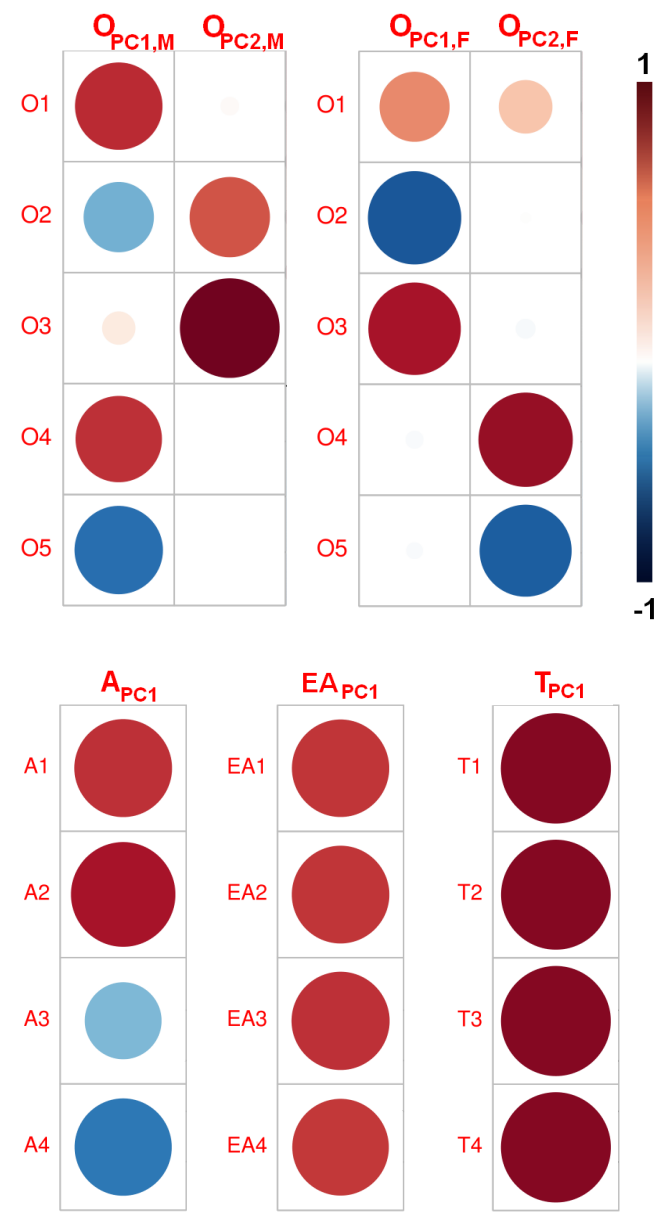

Figure 4: Contributions (i.e. weights) of the embodiment questions to the different components $\left(\mathrm{O}_{P C 1, M}\right.$ and $\mathrm{O}_{P C 2, M}$ (for men), $\mathrm{O}_{P C 1, F}$ and $\mathrm{O}_{P C 2, F}$ (for women), $\mathrm{A}_{P C 1}, \mathrm{EA}_{P C 1}, \mathrm{~T}_{P C 1}$ )

motion (the stabbed hand) during the threat period to determine whether they reacted or not to this threat. More precisely, we computed the accumulated right hand motion between the moment when the knife was above the hand (approximately $0.5 \mathrm{~s}$ before the stab) and the moment when the character removed the knife (approximately $1.5 \mathrm{~s}$ after the stab). Six participants were removed from the analysis because of missing data (controllers positions were not saved), one because he/she removed his/her hand without holding the controller, and one because he/she removed his/her hand before the stab.

Across participants, the average accumulated hand motion was $9.15 \pm 19.7 \mathrm{~cm}$ (median=1.93 $\mathrm{cm} ; \min =1.05 \mathrm{~cm} ; \max =114 \mathrm{~cm})$, which was positively correlated with the threat perception score $(r=0.561, p<0.001)$. In addition, we computed Pearson correlations between the participants' accumulated hand motion and their psychological variables, to determine if their personality traits or abilities would influence the degree to which they reacted to the threat, but we did not find significant correlations.

However, as the threat response can also be considered as a binary variable (whether participants reacted or not), we then performed a further analysis by computing a multiple logistic regression model on whether participants reacted or not. In particular, we considered that participants reacted to the threat if their accumulated hand motion was greater than $5 \mathrm{~cm}$ (threshold experimentally identified from the experimenter's records of whether participants actually reacted). With this criterion, 30 participants were considered to have reacted to the stab out of the 115 participants kept for this analysis. We then used AIC to select the variables to remove from the multiple logistic regression model, and found a model only composed of neuroticism ( $\beta=0.027, p=0.022)$ and chance $\operatorname{LoC}(\beta=-0.062, p=0.140)$.

\subsection{Personality Influence on Presence}

As previously mentioned, we also asked participants to answer presence questionnaires to assess how similar our results on the relation between personality and presence were from previous work, as well as to strengthen potential results on the sense of embodiment.

While we used Polychoric PCA to analyse the results of embodiment, previous work on presence commonly used a simple mean score over the SUS questions. In order to compare our results to previous work, we therefore followed the same procedure. As for the sense of embodiment, we studied Pearson correlations to identify potential links between presence and personality traits. We found positive correlations with agreeableness $(r=0.227, \mathrm{p}=0.012)$ and with the internal LoC $(r=0.203, p=0.024)$.

We performed a multiple linear regression which gave us a model composed of agreeableness, neuroticism, internal LoC and chance LoC (adjusted $R^{2}=0.134, p<0.001$ ).

\subsection{Other Interesting Results}

In order to get a clearer understanding of the potential relations between the different aspects of embodiment, we also computed Pearson correlations between all the components that relate to the sense of embodiment. Across men and women participants, we first found a positive correlation between external appearance $\left(\mathrm{EA}_{P C 1}\right)$ and threat perception $\left(\mathrm{T}_{P C 1}\right)(r=0.327, p<0.001)$, showing that participants tended to be more sensitive to the threat on their avatar when they also rated higher questions on external appearance.

As body ownership analyses were performed separately on men and women, because of significant differences in answering some of the questions, we also looked at correlations separately in this context. First it is interesting to note that we found a positive correlation between external appearance $\left(\mathrm{EA}_{P C 1}\right)$ and all the men and women ownership components $\left(\mathrm{O}_{P C 1, M}: r=0.345, p=0.005\right.$; $\mathrm{O}_{P C 2, M}: r=0.287, p=0.020 ; \mathrm{O}_{P C 1, F}: r=0.564, p<0.001$; $\left.\mathrm{O}_{P C 2, F}: r=0.593, p<0.001\right)$. For both men and women, we also found a correlation between the threat perception $\left(\mathrm{T}_{P C 1}\right)$ and their first ownership component $\left(\mathrm{O}_{P C 1, M}: r=0.355, p=0.004\right.$; $r=0.289, p=0.028$ ).

\section{Discussion}

This experiment on the sense of embodiment, in which 123 participants took part, is to our knowledge the first VR experiment measuring embodiment as well as several personality traits and body awareness. Our aim was to explore how internal factors (individual differences) could modulate virtual embodiment experiences. In this section, we discuss the obtained results for each aspect of embodiment, as well as future work.

\subsection{Sense of Embodiment}

For each aspect, we first discuss the global obtained scores. While we used PCA for the analysis, here we mention scores for the different aspects using summation equations provided by [18] in order to provide a simpler interpretation for discussion. Then we discuss the results concerning the Big Five traits and the locus of control, and finally potential other noticeable results like differences between men and women or interesting correlations with other variables.

\subsubsection{Body Ownership}

Overall, body ownership scores were in the average $(M=4.3 ; S D=$ 1.1 , with a high variability, i.e. people presenting either low or 
Table 2: Pearson correlations for ownership (men and women), agency, external appearance, response to threat and presence

\begin{tabular}{|c|c|c|c|c|c|c|c|}
\hline & $\mathrm{O}_{P C 1, M}$ & $\mathrm{O}_{P C 1, F}$ & $\mathrm{O}_{P C 2, F}$ & $\mathrm{~A}_{P C 1}$ & $\mathrm{EA}_{P C 1}$ & $\mathrm{~T}_{P C 1}$ & Presence \\
\hline Openness & & $-0.293 *$ & & & & & \\
\hline \multicolumn{8}{|l|}{ Conscientiousness } \\
\hline Extraversion & & & & & & & \\
\hline Agreeableness & & & & & & & $0.227 *$ \\
\hline Neuroticism & & & & & & $0.258 * *$ & \\
\hline Internal & & & & $0.248 * *$ & $0.195^{*}$ & & $0.203^{*}$ \\
\hline Powerful others & & & $0.427 * *$ & & & & \\
\hline Chance & $0.248^{*}$ & & $0.366^{* *}$ & & $0.201 *$ & & \\
\hline
\end{tabular}

$(*: p<0.05 ; * *: p<0.01)$

high levels of body ownership. This could be explained either by the individual differences of participants and/or the use of a generic avatar. Our results also show that the question related to the colocated virtual body $(\mathrm{O} 1)$ was rated higher than the question related to the avatar visible in the mirror $(\mathrm{O} 4)$, which seems to suggest that the use of a mirror could be detrimental in some cases, as it might emphasise the appearance differences.

Regarding the influence of personality traits, our results first demonstrated that body ownership is to some extend correlated with external dimensions of the locus of control, both for male and female participants. This result answers Q4, but not as expected. Since the sense of ownership and agency usually strengthen each other, we expected ownership to be correlated with an internal locus of control, as is the case for agency. However, our results suggest that body ownership is actually more influenced by external dimensions of the locus of control. Typically, people with an external locus of control tend to think that things happening to them depend mostly on the influence of other people or chance. Therefore, our results suggest that people with an external locus of control might feel embodied in a virtual representation more easily than people with an internal locus of control.

In conducting this study, we expected some of the Big Five personality traits to influence ownership (Q3). However, our results did not show any evidence of such an influence. Similarly, we also measured body awareness, i.e., the cognitive ability of being aware of body processes, which we supposed could also influence embodiment in general (Q5). Even though body ownership scores tended to be low for people with high body awareness, the results were not significant. Similarly, experience in VR and video games, which could have influenced body ownership, did not show any influence, suggesting that experience in virtual-type applications does not influence how one's accept a virtual body as its own.

Finally, we also noticed that women gave higher scores to the question O5, which means that they had a higher feeling that the avatar in the mirror was someone else. It is difficult to assess what might explain this result, but a possible assumption would be the fact that the avatars were not personalised. More precisely, it is possible that the male avatar had more average physical characteristics regarding the population of the experiment than the female avatar (brown hair and average build for male avatar compared to blond hair and skinny body for female avatar). While this result shows that differences can appear between different user groups as it was previously found in other studies [60], and that the visual resemblance of the avatar might also influence these results, further studies would be necessary to better understand these influences.

\subsubsection{Agency}

On average, agency scores were high $(M=5.1 ; S D=0.7)$, showing that participants felt in control of the avatar's movements. First, we found that the sense of agency is correlated with the internal dimension of the locus of control, which positively answers our question Q3 and is in line with previous findings [26]. Therefore, it seems that people who feel a higher control on happening events tend to also experience a higher control of their virtual body, and might therefore feel more responsible of the avatar's movements. However, we did not find correlations with the other personality traits from the Big Five. Interestingly, we also found a positive correlation with the level of experience in video games, showing that the more people have experience in video games, the more they feel they have control over their avatar. This result is also supported by participants (with high gaming experience) feedback, who reported that they felt in control both because the avatar was moving well according to their movements and because they felt that there was no latency in the displayed movements.

\subsubsection{External Appearance}

External appearance scores were overall below average $(M=3.0$; $S D=1.3$ ), meaning that participants did not really have the feeling that the avatar looked like them. Our results showed that the acceptance of the avatar's external appearance was positively correlated with the internal and the chance dimensions of the locus of control. This result is particularly surprising as it shows that external appearance is simultaneously influenced by opposite (internal and external) types of locus of control. However, further exploration showed that these effects were due to external appearance being more correlated with an internal locus of control for men, but with a chance locus for women. However, these results cannot be interpreted in terms of differences between men and women's personality traits and can only be interpreted separately. Women with a chance locus of control tend to have higher external appearance scores, i.e., they tend to think that the self-avatar is a look-alike avatar. This result is similar to the one obtained for ownership, which was also correlated for women with an external locus of control and could be explained for the same reasons evoked previously. In contrary, men with an internal locus of control tended to have higher external appearance score. This means that men thinking that they can control their own life tend to more believe their avatar is similar to them. Although those interesting results also highlight differences between groups of population, deeper studies would be required to clarify these effects.

\subsubsection{Threat Perception}

Threat perception scores were particularly low $(M=2.9 ; S D=2.0)$, which is in accordance with the number of people who actually reacted to the stab ( 30 out of 115 whose reactions to the threat were recorded). This is supported by the feedback from several participants who did not react to the threat and reported that they felt that the virtual environment seemed "safe", and therefore did not feel threatened. Moreover, we found that threat perception was correlated with neuroticism. Since people with a high degree of neuroticism tend to be anxious, it is understandable that these same 
people were more impacted by the introduction of the threat. The fear of a threat is also commonly considered as an expression of the sense of ownership in studies exploring the sense of embodiment. If we did observed in our results that the threat perception was also correlated with one component of ownership for both men and women, it is however not enough to make a link between neuroticism and the sense of ownership.

In addition to assessing threat through questionnaires, we also measured the right hand motion in reaction to the stab. The model which better explained the differences between people who reacted from those who did not react was also influenced by neuroticism, which confirms the influence of neuroticism on the response to threat.

\subsection{Presence}

Our goal in investigating whether we found similar effects of personality traits on presence than previous studies was to validate that our experimental setup provided a similar basis than previous studies, which would therefore simultaneously strengthen the value of any results found for the influence of personality traits on the sense of embodiment. As expected, we found similar correlations than in previous studies, namely a correlation between presence and agreeableness [58], as well as between presence and an internal locus of control [74].

\subsection{Future Work}

The different aspects of embodiment are very complex processes, and our results confirm the fact that more studies are required to further our understanding of these processes. In particular, while we expected personality traits or cognitive abilities to enable us to explain why some people easily believe in the illusion of being embodied in a virtual body, and why others are in the contrary totally refractory, we found that mostly the locus of control personality trait was able to explain some of these differences. Therefore, we are still far from uncovering all the mechanisms involved in eliciting high senses of embodiment in every user, which would also require further inter-disciplinary collaborations. For example, cognitive models trying to explain the sense of ownership is still an on-going topic of research evolving regularly [6] and involving different theories.

In this experiment, we decided to investigate individual factors in relation to the sense of embodiment, which had not been deeply explored yet in virtual reality. For the first study on this topic, we therefore chose a number of questionnaires to explore the potential influence of personality traits. Given the amount of personality and cognitive models and questionnaires in the literature, it was therefore not possible to be exhaustive, and we decided to focus on some of the most common models (i.e., Big Five, Locus of Control, Body Awareness). Further studies exploring the influence of other traits and inter-personal aspects could also be interesting to improve our understanding, e.g., absorption, empathy, cultural differences, racial information.

In this study, we also chose to focus on a standard visuomotor task, as it was previously shown to be stronger than visuotactile synchronisation to induce body ownership. Conducting similar experiments with more complex tasks would therefore also be of interest, e.g., to evaluate the influence of the cognitive load or of the type of stimulation. For instance, people reported that they tended to forget the avatar while doing the task, therefore exploring tasks involving more the actual user's virtual representation would also be interesting.

Finally, one interest of our experiment was to explore whether our results could suggest the use of a novel pre-experiment questionnaire to assess/predict the degree to which users would feel embodied in their avatar. For this reason, we included both a longer and a shorter version of the Big Five personality questionnaires (i.e., BFI and TIPI), in order to evaluate if a shorter questionnaire could lead to similar results in assessing the sense of embodiment from personality traits. While our current results were not conclusive in this regard (Q1, Q2), to be able to create such a questionnaire could prove a valuable tool in the future to adapt the virtual experience to the user in order to maximise his/her sense of embodiment. This would however also require additional knowledge about which adaptations are more fitted for some categories of users than others.

\section{CONCLUSION}

In this paper, we presented a first experiment exploring the influence of several personality traits and body awareness on the sense of embodiment. Overall, our main results suggest that the locus of control is correlated with some of its components: an internal locus of control is correlated with agency, while an external locus of control seems to be linked to body ownership. While the locus of control provides some information about the sense of embodiment, our results suggest that Big Five personality traits and body awareness are not the main influencing factors. We only found a positive correlation between neuroticism and the reaction to threat (both in embodiment questionnaires and in actual behavioural responses). This study is therefore another step towards a better understanding of the sense of embodiment. In particular, we would like in the future to be able to exploit the user's profile to offer him a customised experience, such as adding cues enhancing body ownership in cases when the user is considered to be unresponsive to body ownership. Another possibility could also involve increasing other aspects, such as presence or enjoyment, for people who are refractory to some aspects of the embodiment, instead of desperately attempt to elicit this illusion.

\section{ACKNOWLEDGMENTS}

We wish to thank all the reviewers for their constructive comments, as well as the participants who took part in our experiment. This work was sponsored by the Inria IPL Avatar project.

\section{REFERENCES}

[1] F. Argelaguet, L. Hoyet, M. Trico, and A. Lécuyer. The role of interaction in virtual embodiment: Effects of the virtual hand representation. In IEEE Virtual Reality, pp. 3-10. Greenville, United States, 2016.

[2] T. Asai, Z. Mao, E. Sugimori, and Y. Tanno. Rubber hand illusion, empathy, and schizotypal experiences in terms of self-other representations. Consciousness and Cognition, 20(4):1744 - 1750, 2011. From Dreams to Psychosis: A European Science Foundation Exploratory Workshop.

[3] D. Banakou, R. Groten, and M. Slater. Illusory ownership of a virtual child body causes overestimation of object sizes and implicit attitude changes. Proceedings of the National Academy of Sciences, 110(31):12846-12851, 2013.

[4] R. Baños, C. Botella, A. García-Palacios, H. Villa, C. Perpiñá, and M. Gallardo. Psychological variables and reality judgment in virtual environments: The roles of absorption and dissociation. CyberPsychology \& Behavior, 2(2):143-148, 1999. PMID: 19178250.

[5] M. Botvinick and J. Cohen. Rubber hands 'feel' touch that eye sees. Nature, 391:756, 1998.

[6] N. Braun, S. Debener, N. Spychala, E. Bongartz, P. Sörös, H. H. O. Müller, and A. Philipsen. The Senses of Agency and Ownership: A Review. Frontiers in Psychology, 9:535, 2018.

[7] J.-F. Bélisle and H. O. Bodur. Avatars as information: Perception of consumers based on their avatars in virtual worlds. Psychology \& Marketing, 27(8):741-765, 2010.

[8] J. Chen, G. A. Lee, M. Billinghurst, R. W. Lindeman, and C. Bartneck. The Effect of User Embodiment in AV Cinematic Experience. In R. W. Lindeman, G. Bruder, and D. Iwai, eds., ICAT-EGVE 2017 International Conference on Artificial Reality and Telexistence and Eurographics Symposium on Virtual Environments. The Eurographics Association, 2017. 
[9] N. David, F. Fiori, and S. M. Aglioti. Susceptibility to the rubber hand illusion does not tell the whole body-awareness story. Cognitive, affective and behavioral neuroscience, 141:297-306, 2014.

[10] F. de Vignemont. Embodiment, ownership and disownership. Consciousness and Cognition, 20(1):82 - 93, 2011. Brain and Self: Bridging the Gap.

[11] H. G. Debarba, R. Boulic, R. Salomon, O. Blanke, and B. Herbelin. Self-attribution of distorted reaching movements in immersive virtual reality. Computers \& Graphics, 76:142 - 152, 2018.

[12] M. H. Draper, M. J. Wells, V. J. Gawron, and I. Tom A. Furness. Exploring the influence of a virtual body on spatial awareness. Proceedings of the Human Factors and Ergonomics Society Annual Meeting, 40(22):1146-1150, 1996.

[13] T. Dummer, A. Picot-Annand, T. Neal, and C. Moore. Movement and the Rubber Hand Illusion. Perception, 38(2):271-280, 2009. PMID 19400435.

[14] L. Dumont. Expérience subjective et différences individuelles dans l'intégration d'informations visuelle et kinesthésique. Master's thesis, Université de Montréal, Canada, 2013.

[15] H. H. Ehrsson, K. Wiech, N. Weiskopf, R. J. Dolan, and R. E. Passingham. Threatening a rubber hand that you feel is yours elicits a cortical anxiety response. Proceedings of the National Academy of Sciences, 104(23):9828-9833, 2007.

[16] J. J. Faraway. Extending the linear model with R: generalized linear, mixed effects and nonparametric regression models, second edition. Chapman \& Hall/CRC, 2004.

[17] L. R. Goldberg. An alternative "description of personality": The bigfive factor structure. Journal of personality and social psychology, 59:1216-29, 1991. doi: 10.1037//0022-3514.59.6.1216

[18] M. González-Franco and T. C. Peck. Avatar embodiment. towards a standardized questionnaire. Frontiers in Robotics and AI, 5:74, 2018. doi: 10.3389/frobt.2018.00074

[19] M. González-Franco, D. Pérez-Marcos, B. Spanlang, and M. Slater. The contribution of real-time mirror reflections of motor actions on virtual body ownership in an immersive virtual environment. In 2010 IEEE Virtual Reality Conference (VR), pp. 111-114, 2010. doi: 10 1109/VR.2010.5444805

[20] G. Gorisse, O. Christmann, E. A. Amato, and S. Richir. First- and third-person perspectives in immersive virtual environments: Presence and performance analysis of embodied users. Frontiers in Robotics and $A I, 4: 33$, 2017. doi: 10.3389/frobt.2017.00033

[21] G. Gorisse, O. Christmann, S. Houzangbe, and S. Richir. From robot to virtual doppelganger: Impact of visual fidelity of avatars controlled in third-person perspective on embodiment and behavior in immersive virtual environments. Frontiers in Robotics and AI, 6:8, 2019. doi: 10 . 3389/frobt.2019.00008

[22] S. Gosling, P. Rentfrow, and W. Swann, Jr. A very brief measure of the big five. Personality Domains. Journal of Research in Personality, 37:504-528, 2003.

[23] P. Heidicker, E. Langbehn, and F. Steinicke. Influence of avatar appearance on presence in social vr. In 2017 IEEE Symposium on $3 D$ User Interfaces (3DUI), pp. 233-234, 2017.

[24] P. H. Jacques, J. Garger, C. A. Brown, and C. S. Deale. Personality and virtual reality team candidates: The roles of personality traits, technology anxiety and trust as predictors of perceptions of virtual reality teams. Journal of Business and Management, 15(2):143, 2009.

[25] P. M. Jenkinson and C. Preston. New reflections on agency and body ownership: The moving rubber hand illusion in the mirror. Conscious ness and Cognition, 33:432 - 442, 2015. doi: 10.1016/j.concog. 2015. 02.020

[26] C. Jeunet, L. Albert, F. Argelaguet, and A. Lécuyer. " Do you feel in control?" : Towards Novel Approaches to Characterise, Manipulate and Measure the Sense of Agency in Virtual Environments. IEEE Transactions on Visualization and Computer Graphics, 24(4):14861495, 2018. doi: 10.1109/TVCG.2018.2794598

[27] O. John, E. Donahue, and R. Kentle. The big five inventory-versions 4a and 54. 1991

[28] O. P. John and S. M. Srivastava. The big-five trait taxonomy: History, measurement, and theoretical perspectives. In Handbook of personality: Theory and research, 1999.
[29] I. Jurnet, C. Carvallo Beciu, and J. Gutiérrez-Maldonado. Individual differences in the sense of presence. Proceedings of Presence 2005: The 8th International Workshop on Presence, pp. 133-142, 2005.

[30] A. Kalckert and H. Ehrsson. Moving a rubber hand that feels like your own: A dissociation of ownership and agency. Frontiers in human neuroscience, 6:40, 2012. doi: 10.3389/fnhum.2012.00040

[31] K. Kilteni, R. Groten, and M. Slater. The sense of embodiment in virtual reality. Presence: Teleoperators and Virtual Environments, 21(4):373-387, 2012. doi: 10.1162/PRES_a_00124

[32] S. E. Kober and C. Neuper. Personality and presence in virtual reality: Does their relationship depend on the used presence measure? International Journal of Human-Computer Interaction, 29(1):13-25, 2013. doi: 10.1080/10447318.2012.668131

[33] E. Kokkinara and M. Slater. Measuring the Effects through Time of the Influence of Visuomotor and Visuotactile Synchronous Stimulation on a Virtual Body Ownership Illusion. Perception, 43(1):43-58, 2014. PMID: 24689131. doi: 10.1068/p7545

[34] R. Kondo, M. Sugimoto, K. Minamizawa, T. Hoshi, M. Inami, and M. Kitazaki. Illusory body ownership of an invisible body interpolated between virtual hands and feet via visual-motor synchronicity. Scientific Reports, 8, 2018.

[35] J. Kállai, G. Hegedüs, Ádám Feldmann, S. Rózsa, G. Darnai, R. Herold, K. Dorn, P. Kincses, Árpád Csathó, and T. Szolcsányi. Temperament and psychopathological syndromes specific susceptibility for rubber hand illusion. Psychiatry Research, 229(1):410 - 419, 2015. doi: 10. 1016/j.psychres.2015.05.109

[36] J. Laarni, N. Ravaja, T. Saari, and T. Hartmann. Personality-Related Differences in Subjective Presence, pp. 88-95. Technical University of Valencia, 2004.

[37] B. Laha, J. N. Bailenson, A. S. Won, and J. O. Bailey. Evaluating control schemes for the third arm of an avatar. Presence: Teleoperators and Virtual Environments, 25(2):129-147, 2016. doi: 10.1162/PRES_a -00251

[38] B. Lenggenhager, T. Tadi, T. Metzinger, and O. Blanke. Video ergo sum: Manipulating bodily self-consciousness. Science, 317(5841):10961099, 2007. doi: 10.1126/science. 1143439

[39] H. Levenson. Differentiating among internality, powerful others and chance. In H. M. Lefcourt, ed., Research with the locus of control construct, vol. 1, pp. 15-63. New York: Academic Press, 1981.

[40] Y. Ling, H. T. Nefs, W.-P. Brinkman, C. Qu, and I. Heynderickx. The relationship between individual characteristics and experienced presence. Computers in Human Behavior, 29(4):1519 - 1530, 2013. doi: 10.1016/j.chb.2012.12.010

[41] G. Loas, R. Dardennes, P. Dhee-Perot, V. Leclerc, and D. Fremaux. Opérationnalisation du concept de "lieu de contrôle": traduction et première étude de validation de l'échelle de contrôle de Levenson (IPC: the internal powerful others and chance scale). Annales médicopsychologiques, 152(7):466-9, 1994.

[42] M. R. Longo, F. Schüür, M. P. Kammers, M. Tsakiris, and P. Haggard. What is embodiment? A psychometric approach. Cognition, 107(3):978 - 998, 2008. doi: 10.1016/j.cognition.2007.12.004

[43] E. M. Bernstein and F. W. Putnam. Development, reliability, and validity of a dissociation scale. The Journal of nervous and mental disease, 174:727-35, 1987.

[44] M. Martini, D. Perez-Marcos, and M. Sanchez-Vives. Modulation of pain threshold by virtual body ownership. European Journal of Pain, 18(7):1040-1048, 2014. doi: 10.1002/j.1532-2149.2014.00451.x

[45] A. Maselli and M. Slater. The building blocks of the full body ownership illusion. Frontiers in Human Neuroscience, 7:83, 2013. doi: 10. 3389/fnhum.2013.00083

[46] A. Maselli and M. Slater. Sliding perspectives: dissociating ownership from self-location during full body illusions in virtual reality. Frontiers in Human Neuroscience, 8:693, 2014. doi: 10.3389/fnhum.2014.00693

[47] E. A. McManus, B. Bodenheimer, S. Streuber, S. de la Rosa, H. H. Bülthoff, and B. J. Mohler. The influence of avatar (self and character) animations on distance estimation, object interaction and locomotion in immersive virtual environments. In Proceedings of the ACM SIGGRAPH Symposium on Applied Perception in Graphics and Visualization, APGV '11, pp. 37-44. ACM, New York, NY, USA, 2011. doi: 10. $1145 / 2077451.2077458$ 
[48] W. E. Mehling, V. Gopisetty, J. Daubenmier, C. J. Price, F. M. Hecht, and A. Stewart. Body awareness: Construct and self-report measures. PLOS ONE, 4(5):1-18, 2009. doi: 10.1371/journal.pone.0005614

[49] C. D. Murray, J. Fox, and S. Pettifer. Absorption, dissociation, locus of control and presence in virtual reality. Computers in Human Behavior, 23(3): 1347 - 1354, 2007. Including the Special Issue: Avoiding Simplicity, Confronting Complexity: Advances in Designing Powerful Electronic Learning Environments. doi: 10.1016/j.chb.2004.12.010

[50] S. G. Nicovich, G. W. Boller, and T. B. Cornwell. Experienced presence within computer-mediated communications: Initial explorations on the effects of gender with respect to empathy and immersion. Journal of Computer-Mediated Communication, 10(2):00-00, 2005. doi: 10. 1111/j.1083-6101.2005.tb00243.x

[51] T. C. Peck, S. Seinfeld, S. M. Aglioti, and M. Slater. Putting yourself in the skin of a black avatar reduces implicit racial bias. Consciousness and Cognition, 22(3):779 - 787, 2013. doi: 10.1016/j.concog.2013.04. 016

[52] A. Peled, M. Ritsner, S. Hirschmann, A. B. Geva, and I. Modai Touch feel illusion in schizophrenic patients. Biological Psychiatry, 48(11): 1105 - 1108, 2000. doi: 10.1016/S0006-3223(00)00947-1

[53] V. I. Petkova and H. H. Ehrsson. If I Were You: Perceptual Illusion of Body Swapping. PLOS ONE, 3(12):1-9, 2008. doi: 10.1371/journal. pone. 0003832

[54] L. Phillips, V. Interrante, M. Kaeding, B. Ries, and L. Anderson. Correlations between physiological response, gait, personality, and presence in immersive virtual environments. Presence, 21(2):119-141, 2012. doi: 10.1162/PRES_a_00100

[55] O. Plaisant, R. Courtois, R. Réveillère, G. Mendelsohn, and O.-P. John Validation du big five inventory français (inventaire des cinq grandes dimensions de la personnalité). Annales Medico-psychologiques, 10(1016), 2010.

[56] D. Rabellino, S. Harricharan, P. A. Frewen, D. Burin, M. C. McKinnon, and R. A. Lanius. "I can't tell whether it's my hand": a pilot study of the neurophenomenology of body representation during the rubber hand illusion in trauma-related disorders. In European journal of psychotraumatology, 2016.

[57] Y. Rybarczyk, T. Coelho, T. Cardoso, and R. de Oliveira. Effect of avatars and viewpoints on performance in virtual world: efficiency vs. telepresence. EAI Endorsed Trans. Creative Technologies, 1:e4, 2014.

[58] A. Sacau, J. Laarni, N. Ravaja, and T. Hartmann. The impact of personality factors on the experience of spatial presence. Presence, 2005.

[59] C. Sas and G. M. P. O'Hare. Presence equation: An investigation into cognitive factors underlying presence. Presence: Teleoperators and Virtual Environments, 12(5):523-537, 2003. doi: 10.1162 105474603322761315

[60] V. Schwind, P. Knierim, C. Tasci, P. Franczak, N. Haas, and N. Henze. "These Are Not My Hands!": Effect of Gender on the Perception of Avatar Hands in Virtual Reality. In Proceedings of the 2017 CHI Conference on Human Factors in Computing Systems, CHI '17, pp. 1577-1582. ACM, New York, NY, USA, 2017.

[61] A. Seiryte and E. Rusconi. The empathy quotient (eq) predicts perceived strength of bodily illusions and illusion-related sensations of pain. Personality and Individual Differences, 77:112 - 117, 2015. doi: 10.1016/j.paid.2014.12.048

[62] S. Shields, M. E. Mallory, and A. Simon. The body awareness questionnaire: Reliability and validity. Journal of Personality Assessment 53:802-815, 1989

[63] M. Slater, X. Navarro, J. Valenzuela, R. Oliva, A. Beacco, J. Thorn, and Z. Watson. Virtually Being Lenin Enhances Presence and Engagement in a Scene From the Russian Revolution. Frontiers in Robotics and AI, 5:91, 2018.

[64] M. Slater, D. Perez-Marcos, H. H. Ehrsson, and M. V. Sanchez-Vives. Towards a digital body: the virtual arm illusion. Frontiers in human neuroscience, 2:6, 2008.

[65] M. Slater, B. Spanlang, M. V. Sanchez-Vives, and O. Blanke. First person experience of body transfer in virtual reality. PLOS ONE, $5(5): 1-9,2010$.

[66] M. Slater and M. Usoh. The influence of a virtual body on presence in immersive virtual environments. In VR 93, Virtual Reality International,
Proceedings of the Third Annual Conference on Virtual Reality, pp. 34-42, 1993.

[67] M. Slater and M. Usoh. Representations systems, perceptual position, and presence in immersive virtual environments. Presence, 2:221-233, 1993. doi: 10.1162/pres.1993.2.3.221

[68] M. Storme, J. L. Tavani, and N. Myszkowski. Psychometric properties of the french ten-item. Personality Inventory (TIPI). Journal of Individual Differences, 37:81-87, 2016.

[69] A. Tellegen and G. Atkinson. Openness to absorbing and self altering experiences ('absorption'), a trait related to hypnotic susceptibility. Journal of abnormal psychology, 83:268-77, 1974.

[70] K. N. Thakkar, H. S. Nichols, L. G. McIntosh, and S. Park. Disturbances in body ownership in schizophrenia: Evidence from the rubber hand illusion and case study of a spontaneous out-of-body experience. PLOS ONE, 6(10):1-9, 2011.

[71] M. Tsakiris, G. Prabhu, and P. Haggard. Having a body versus moving your body: How agency structures body-ownership. Consciousness and Cognition, 15(2):423 - 432, 2006.

[72] M. Usoh, E. Catena, S. Arman, and M. Slater. Using presence questionnaires in reality. Presence: Teleoperators and Virtual Environments, 9(5):497-503, 2000

[73] G. Van Doorn, A. De Foe, A. Wood, D. Wagstaff, and J. Hohwy. Down the rabbit hole: assessing the influence of schizotypy on the experience of the barbie doll illusion. Cognitive Neuropsychiatry, 23(5):284-298, 2018. cited By 1 .

[74] H. S. Wallach, M. P. Safir, and R. Samana. Personality variables and presence. Virtual Reality, 14(1):3-13, 2010.

[75] T. Waltemate, D. Gall, D. Roth, M. Botsch, and M. E. Latoschik. The impact of avatar personalization and immersion on virtual body ownership, presence, and emotional response. IEEE Transactions on Visualization and Computer Graphics, 24(4):1643-1652, 2018.

[76] D. Weibel, B. Wissmath, and F. W. Mast. Immersion in mediated environments: The role of personality traits. Cyberpsychology, Behavior, and Social Networking, 13(3):251-256, 2010. PMID: 20557243.

[77] A. C. Wellerdiek, M. Leyrer, E. Volkova, D.-S. Chang, and B. Mohler. Recognizing your own motions on virtual avatars. In Proceedings of the ACM Symposium on Applied Perception - SAP '13, p. 138. ACM Press, New York, New York, USA, 2013.

[78] N. Yee and J. Bailenson. The Proteus Effect: The Effect of Transformed Self-Representation on Behavior. Human Communication Research, $33: 271-290,2007$ 


\section{A Appendix A - Multiple linear Regression models}

Table 3: Multiple linear regression models for embodiment $(*: p<0.05 ; * *: p<0.01 ; * * *: p<0.001)$

$\mathbf{O}_{P C 1, M}$

\begin{tabular}{lrl} 
Variables & $\beta$ & $\operatorname{Pr}(>|t|)$ \\
\hline \hline Internal & 0.059 & $0.003 * *$ \\
Chance & 0.054 & $0.004 * *$ \\
Body Awareness & -0.013 & $0.038 *$
\end{tabular}

$\mathbf{O}_{P C 1, F}$

\begin{tabular}{lrl} 
Variables & $\beta$ & $\operatorname{Pr}(>|t|)$ \\
\hline \hline Openness & -0.010 & $0.021 *$ \\
Conscientiousness & -0.008 & 0.068 \\
Internal & 0.038 & $0.006 * *$ \\
Powerful & -0.026 & 0.055 \\
Chance & 0.038 & $0.010 * *$ \\
Body Awareness & -0.010 & $0.044 *$
\end{tabular}

$\mathbf{O}_{P C 2, F}$

\begin{tabular}{lrl} 
Variables & $\beta$ & $\operatorname{Pr}(>|t|)$ \\
\hline \hline Extraversion & 0.006 & 0.112 \\
Powerful & 0.036 & $0.024^{*}$ \\
Chance & 0.027 & 0.099 \\
Body Awareness & -0.008 & 0.174
\end{tabular}

$\mathbf{A}_{P C 1}$

\begin{tabular}{lrl} 
Variables & $\beta$ & $\operatorname{Pr}(>|t|)$ \\
\hline \hline Agreeableness & 0.005 & 0.122 \\
Internal & 0.026 & $0.003 * *$ \\
Body Awareness & -0.006 & 0.077
\end{tabular}

$\mathbf{E A}_{P C 1}$ for men

\begin{tabular}{lrl} 
Variables & $\beta$ & $\operatorname{Pr}(>|t|)$ \\
\hline \hline Neuroticism & 0.285 & $0.036^{*}$ \\
Internal & 1.865 & $0.001^{* * *}$ \\
Chance & 0.843 & 0.102
\end{tabular}

$\mathbf{E A}_{P C 1}$ for women

\begin{tabular}{lrl} 
Variables & $\beta$ & $\operatorname{Pr}(>|t|)$ \\
\hline \hline Chance & 1.230 & $0.017 *$
\end{tabular}

$\mathbf{T}_{P C 1}$

\begin{tabular}{lrl} 
Variables & $\beta$ & $\operatorname{Pr}(>|t|)$ \\
\hline \hline Agreeableness & 0.465 & $0.029 *$ \\
Neuroticism & 0.457 & $0.002 * *$
\end{tabular}

Table 4: Multiple linear regression models for presence

\section{Presence}

\begin{tabular}{lrl} 
Variables & $\beta$ & $\operatorname{Pr}(>|t|)$ \\
\hline \hline Agreeableness & 0.018 & $0.008 * *$ \\
Neuroticism & 0.008 & 0.095 \\
Internal & 0.061 & $0.001 * *$ \\
Chance & 0.046 & $0.010 *$
\end{tabular}

\section{B Appendix B - Principal Components Values}

Table 5: Contributions (i.e. weights) of the different questions to the men ownership components

\begin{tabular}{lrr}
\hline & $\mathrm{O}_{P C 1, M}$ & $\mathrm{O}_{P C 2, M}$ \\
\hline $\mathrm{O} 1$ & 0.740 & \\
$\mathrm{O} 2$ & -0.475 & 0.623 \\
$\mathrm{O} 3$ & 0.102 & 0.966 \\
$\mathrm{O} 4$ & 0.722 & \\
$\mathrm{O} 5$ & -0.756 & \\
\hline
\end{tabular}

Table 6: Contributions of the different questions to the women ownership components

\begin{tabular}{lrr}
\hline & $\mathrm{O}_{P C 1, F}$ & $\mathrm{O}_{P C 2, F}$ \\
\hline $\mathrm{O} 1$ & 0.471 & 0.272 \\
$\mathrm{O} 2$ & -0.846 & \\
$\mathrm{O} 3$ & 0.829 & \\
$\mathrm{O} 4$ & & 0.864 \\
$\mathrm{O} 5$ & & -0.822 \\
\hline
\end{tabular}

Table 7: Contributions of the different questions to the agency component

\begin{tabular}{lr}
\hline & $\mathrm{A}_{P C 1}$ \\
\hline $\mathrm{A} 1$ & 0.722 \\
$\mathrm{~A} 2$ & 0.827 \\
$\mathrm{~A} 3$ & -0.443 \\
$\mathrm{~A} 4$ & -0.713 \\
\hline
\end{tabular}

Table 8: Contributions of the different questions to the external appearance component

\begin{tabular}{lc}
\hline & EA $_{P C 1}$ \\
\hline EA1 & 0.716 \\
EA2 & 0.719 \\
EA3 & 0.727 \\
EA4 & 0.705 \\
\hline
\end{tabular}

Table 9: Contributions of the different questions to the threat perception component

\begin{tabular}{lc}
\hline & $\mathrm{T}_{P C 1}$ \\
\hline T1 & 0.919 \\
T2 & 0.913 \\
T3 & 0.915 \\
T4 & 0.917 \\
\hline
\end{tabular}

